\title{
Influência de veranico na produção agrícola no município de Santa Filomena, Piauí, Brasil
}

\section{Influence of veranico in agricultural production in the Santa Filomena city, Piauí state, Brazil}

\author{
Hudson Ellen Alencar Menezes* ${ }^{1}$, Raimundo Mainar de Medeiros ${ }^{2}$, José Lucas Guilherme Santos $^{3}$; Tiago Silva Lima ${ }^{3}$; \\ Thiago Alves Pimenta ${ }^{3}$
}

Resumo: O objetivo deste estudo foi verificar a relação entre a duração, em dias, dos maiores veranicos, e as produções de arroz, cana-de-açúcar, fava, feijão, mandioca, milho, banana e laranja para Santa Filomena - PI. Os dados utilizados consistem de séries diárias de precipitação do posto pluviométrico localizado em Santa Filomena - PI e gentilmente cedido pela empresa de assistência técnica e extensão rural do estado do Piauí (EMATER) para o período de dezembro de 1992 a março de 2010 e de produção agrícola anual das referidas culturas disponibilizadas pelo Instituto Brasileiro de Geografia e Estatística (IBGE) para o período de 1993 a 2010. Considerou-se veranico como sendo o número de dias consecutivos sem chuva ou com chuva abaixo de $2,0 \mathrm{~mm} /$ dia. E o mais longo período de veranico da estação chuvosa (dezembro a março), não havendo quebra entre os meses. Resultou-se que as produções de milho e banana no município de Santa Filomena - PI apresentaram relações diretamente proporcionais aos maiores veranicos ocorridos no período estudado. A produção de laranja foi inversamente proporcional aos maiores veranicos e as produções de arroz, cana-deaçúcar, fava, feijão e mandioca foram independentes da duração de veranicos.

Palavras-chave: Produção agrícola, Precipitação, Correlação.

\begin{abstract}
The objective of this study was to investigate the relationship between the duration in days, the biggest dry spells, and the production of rice, sugarcane, broad bean, bean, cassava, corn, banana and orange for Santa Filomena PI city. The data used consist of daily rainfall station precipitation series located in Santa Filomena - PI city and kindly provided by the service company and extension of the Piauí state (EMATER) for the period December 1992 to March 2010 and production annual agricultural cultures of those offered by the Brazilian Institute of Geography and Statistics (IBGE) for the period 1993 to 2010. It was considered dry spells as the number of consecutive days without rain or rain below $2.0 \mathrm{~mm} /$ day. And the longest dry spell period of the rainy season (December to March), with no breaks between the months. It resulted that the corn and banana production in Santa Filomena - PI city presented directly proportional relationship to the larger dry spells occurred during the study period. The orange production was inversely proportional to dry spells higher productions and rice, sugarcane, broad bean, bean and cassava were independent of the duration dry spells.
\end{abstract}

Keywords: Agricultural production, Rainfall, Correlation.

\footnotetext{
*Autor para correspondência

Recebido para publicação em 20/09/2015; aprovado em 23/12/2015

${ }^{1}$ Doutor em Meteorologia, UFCG, Campina Grande - PB, Brasil, e-mail: hudson.ellen@ufcg.edu.br

${ }^{2}$ Doutor em Meteorologia, UFCG, Campina Grande - PB,Brasil, email:mainarmedeiros@gmail.com

${ }^{3}$ Graduandos em Agronomia, UFCG, Pombal - PB, Brasil, e-mail: lucas1guilherme@ @otmail.com; lima_tiago92@outlook.com; pimenta62@gmail.com
} 


\section{INTRODUÇÃO}

A variabilidade dos índices pluviométricos registrados na região Nordeste do Brasil, particularmente entre as regiões semiárida, cerrado e cerradão, vem causando prejuízo ao setor agropecuário e a parte econômica da região. Apesar de chover tanto quanto em muitas outras regiões do mundo, as referidas regiões sofrem por causa de sua distribuição espaço-temporal e das suas magnitudes de intensidades dos índices pluviométricos que vem ocorrendo.

As regiões são periodicamente afetadas pela ocorrência de secas agrícolas e/ou hidrológicas de elevado grau de severidade, causando perdas parciais ou totais da agropecuária, além de comprometer o abastecimento de água à população. Isto se deve principalmente a irregularidade da estação chuvosa na região, com a predominância de chuvas intensas e de curta duração durante períodos que de 3 a 5 meses.

As ações antropogênicas contribuem diretamente para a redução dos índices pluviométricos e a espera de eventos extremos de chuvas e o aumento no índice da erosão, com a retirada da cobertura vegetal o solo perde sua consistência, pois a água, que antes era absorvida pelas raízes dos vegetais, passa a infiltrar no solo. Esta infiltração pode causar a instabilidade do solo e a erosão.

Os fatores climáticos demonstram influências relevantes no comportamento da variabilidade pluviométrica e da erosividade da precipitação pluviométrica para o município de Matinhas no Estado da Paraíba. A região é afetada por precipitações de origem orográfica e da descida da Zona de Convergência Intertropical (ZCIT), e a contribuição dos efeitos locais com chuvas de longa duração e de baixa a média intensidade, (MOREIRA, 1999; MOREIRA, 2002; VIANELLO; ALVES, 2000).

A variabilidade interanual da pluviometria sobre o Nordeste está associada à interação entre a atmosfera, os oceanos e a fisiografia regional, por exemplo, as variações de padrões de TSM nos oceanos tropicais, as quais afetam a posição e a intensidade da ZCIT sobre o Oceano Atlântico, modulando a pluviometria sobre o norte do Nordeste (MENEZES et al., 2003; NOBRE; MELO, 2001; NOBRE et al., 2001).

Essa grande variabilidade intra-anual e interanual da precipitação são características marcantes no Nordeste brasileiro, outra característica dessa Região é a distribuição espacial irregular. Essa variabilidade climática deve ser considerada em diversos setores, como economia, pecuária, engenharia e produção de energia. A agricultura não é apenas responsável por grande parte das exportações brasileiras e pela geração de milhares de empregos, mas também uma das atividades mais vulneráveis às mudanças climáticas. Os sistemas agrícolas regionais podem ser afetados, com sérias consequências para a produção de alimentos (SILVA et al., 2009).

As grandes culturas são normalmente praticadas em regime de sequeiro, o que as faz depender exclusivamente das precipitações naturais. Com isso, a atividade agrícola torna-se exclusivamente sazonal, sendo praticada principalmente na época das chuvas (SOUSA; FRIZZONE, 1997).
A produtividade de culturas em sistema de sequeiro é altamente dependente das interações entre suas fases fenológicas e as variações interanuais do tempo e clima. Toda cultura plantada nesse sistema depende, inevitavelmente, da quantidade, da distribuição e da intensidade das chuvas. Por outro lado, os fenômenos El Niño e Dipolo influenciam os totais pluviométricos do Nordeste brasileiro; em consequência, contribuem nas variações do rendimento das culturas de subsistência (SILVA et al., 2002).

Fatores como a disponibilidade inadequada d'água as culturas - causada pela evapotranspiração acentuada, associada a falta de um programa governamental de distribuição de água e fomento de técnicas de irrigação - agravam os efeitos das secas, tornando o agricultor cada vez mais sujeito a perdas na produção. Nestas condições, qualquer redução na precipitação anual ou ocorrência de "veranicos" caracterizados pela ocorrência de períodos secos dentro da estação chuvosa - ao longo da estação de cultivo, pode acarretar a perda total ou parcial da produção agrícola. $\mathrm{Na}$ prática, tais situações podem gerar a chamada "seca verde", quando há uma perda quase que total dos cultivos, apesar dos campos cultivados permanecerem verdes.

As informações das condições climáticas de uma determinada região são necessárias para que se possam instituir estratégias, que visem o manejo mais adequado dos recursos naturais, planejando dessa forma, a busca por um desenvolvimento sustentável e a implementação das práticas agrícolas viáveis e seguras para o meio ambiente e a produtividade cítricas.

Segundo Santos et al. (2014) o período chuvoso de Santa Filomena no estado do Piauí inicia-se no mês de outubro, com chuvas de pré-estação, prolongando-se até abril; o trimestre mais chuvoso compreende os meses de dezembro, janeiro e fevereiro.

A previsão da ocorrência de veranicos é bastante significativa para a agropecuária, pois, fornece informações adicionais ao planejamento agrícola tanto de sequeiro quanto irrigado, uma vez que pode auxiliar na maximização do uso eficiente da água nas áreas cultivadas (MENEZES, 2006; MENEZES et al., 2010; CARVALHO et al., 1999).

Com isso Objetivou-se verificar a relação entre a duração, em dias, dos maiores veranicos, e as produções de arroz, cana-de-açúcar, fava, feijão, mandioca, milho, banana e laranja para Santa Filomena no Estado do Piauí.

\section{MATERIAL E MÉTODOS}

Os dados utilizados consistem de séries diárias de precipitação do posto pluviométrico localizado em Santa Filomena - PI e gentilmente cedido pela empresa de assistência técnica e extensão rural do estado do Piauí (EMATER) para o período de dezembro de 1992 a março de 2010 e de produção agrícola anual de arroz (em casca), cana-de-açúcar, fava (em grão), feijão (em grão), mandioca, milho (em grão), banana (cacho) e laranja disponibilizadas pelo Instituto Brasileiro de Geografia e Estatística (IBGE, 2014) para o período de 1993 a 2010.

Considerou-se veranico como sendo o número de dias consecutivos sem chuva ou com chuva abaixo de 2,0 $\mathrm{mm} \operatorname{dia}^{-1}$. E o mais longo da estação chuvosa (dezembro a 
março) segundo Santos et al. (2014), não havendo quebra entre os meses.

Foi verificada uma provável relação entre os maiores veranicos da estação chuvosa de Santa Filomena - PI com a produção de arroz, cana-de-açúcar, fava, feijão, mandioca, milho, banana e laranja.

Qualquer valor de um coeficiente de correlação, não é garantia de que as variáveis envolvidas realmente estejam correlacionadas. Portanto, antes de tirar qualquer conclusão sobre os valores dos coeficientes de correlação é necessário a aplicação de um teste estatístico para conhecer o grau real de ligação entre as variáveis analisadas.

Para tanto, foram estimados os coeficientes de correlação linear $(r)$ entre os maiores veranicos e a produção agrícola no período de 1993 a 2010, utilizandose o teste de significância estatística $t$, de Student.

O teste de hipóteses foi comparado ao valor de coeficiente de correlação calculado com base nos valores críticos determinados a partir da partição da distribuição $t$ de Student. O resultado obtido foi utilizado para sugerir a aceitação da hipótese de nulidade do coeficiente ou não. Nos casos em que o coeficiente de correlação calculado foi igual ou superior ao valor do $\mathrm{t}$ crítico para um determinado grau de liberdade e percentual de significância, a hipótese de nulidade foi rejeitada e a tendência observada é caracterizada como verdadeira para aquele nível de significância obtido (BRUNI, 2007).

Utilizou-se o Método dos Mínimos Quadrados, onde o coeficiente de correlação foi calculado de acordo com Spiegel (1977), Bussab e Morettin (1987) e Morettin (1991) pelas equações 1 e 2

$$
\begin{aligned}
& r= \pm \sqrt{\frac{\text { variação explicada }}{\text { variação total }}} \\
& r=\frac{\mathrm{N} \sum \mathrm{XY}-\left(\sum \mathrm{X}\right)(\Sigma \mathrm{Y})}{\sqrt{\left[\mathrm{N} \sum \mathrm{X}^{2}-\left(\sum \mathrm{X}\right)^{2}\right]\left[\mathrm{N} \Sigma \mathrm{Y}^{2}-(\Sigma \mathrm{Y})^{2}\right]}}
\end{aligned}
$$

Foi aplicado o teste de significância $t$, de Student, com os valores do parâmetro $t$ na equação 3 . $t=\frac{\mathrm{r} \sqrt{\mathrm{N}-2}}{\sqrt{1-\mathrm{r}^{2}}}$

A partir da Equação 3 foi extraído o coeficiente de correlação crítico $\left(\mathrm{r}_{\mathrm{c}}\right)$, que é um valor para o qual aceita ou não a hipótese estatística, $r_{c}$ é dado pela equação 4.

$r_{c}=\sqrt{\frac{t^{2}}{(\mathrm{~N}-2)+t^{2}}}$

Para a correlação entre os maiores veranicos e as produções agrícolas, $\mathrm{N}=18$, ou seja, 18 anos de dados e, $\mathrm{N}-2=16$, que é o grau de liberdade. Logo, os valores de $t$ e $\mathrm{r}_{\mathrm{c}}$ são:

- para 99\% de significância, ou seja, com erro de $1 \%(\alpha=0,01), t=2,92 ; \mathrm{r}_{\mathrm{c}}=0,590$;

- para $95 \%$ de significância, ou seja, com erro de $5 \%(\alpha=0,05), t=2,12 ; \mathrm{r}_{\mathrm{c}}=0,468$.

Isto significa que para os coeficientes de correlação estimados com 16 graus de liberdade, a significância estatística de que realmente há correlação entre as variáveis é de $99 \%$, e assim também para o nível de significância de $95 \%$.

\section{RESULTADOS E DISCUSSÃO}

A Figura 1 apresenta a série temporal dos maiores veranicos ocorridos durante a estação chuvosa de dezembro a março em Santa Filomena - PI, em que o maior veranico verificado foi no ano de2007, com um número de 38 dias consecutivos sem chuva ou com chuva abaixo de $2 \mathrm{~mm} /$ dia.Outros anos com duração de veranicos relativamente altos, de 31 dias, foram os de 2001, 2004, e 2008, ressalta-se também os anos de 2009 (21 dias) e 2010 (22 dias) com veranicos acima de 20 dias.

Os menores veranicos observados ocorreram nos anos de 1999, 2005 e 2006, com 5 apenas dias de duração.

Observa-se na Figura 1 uma tendência linear de aumento da duração dos maiores veranico no município de Santa Filomena - PI para o limiar de $2 \mathrm{~mm}$. A duração média dos maiores veranicos foi de 15 dias.

Figura 1. Série temporal da duração em dias dos maiores veranicos ocorridos durante a estação chuvosa de dezembro a março em Santa Filomena no Estado do Piauí, para limiares menores de $2 \mathrm{~mm}$.

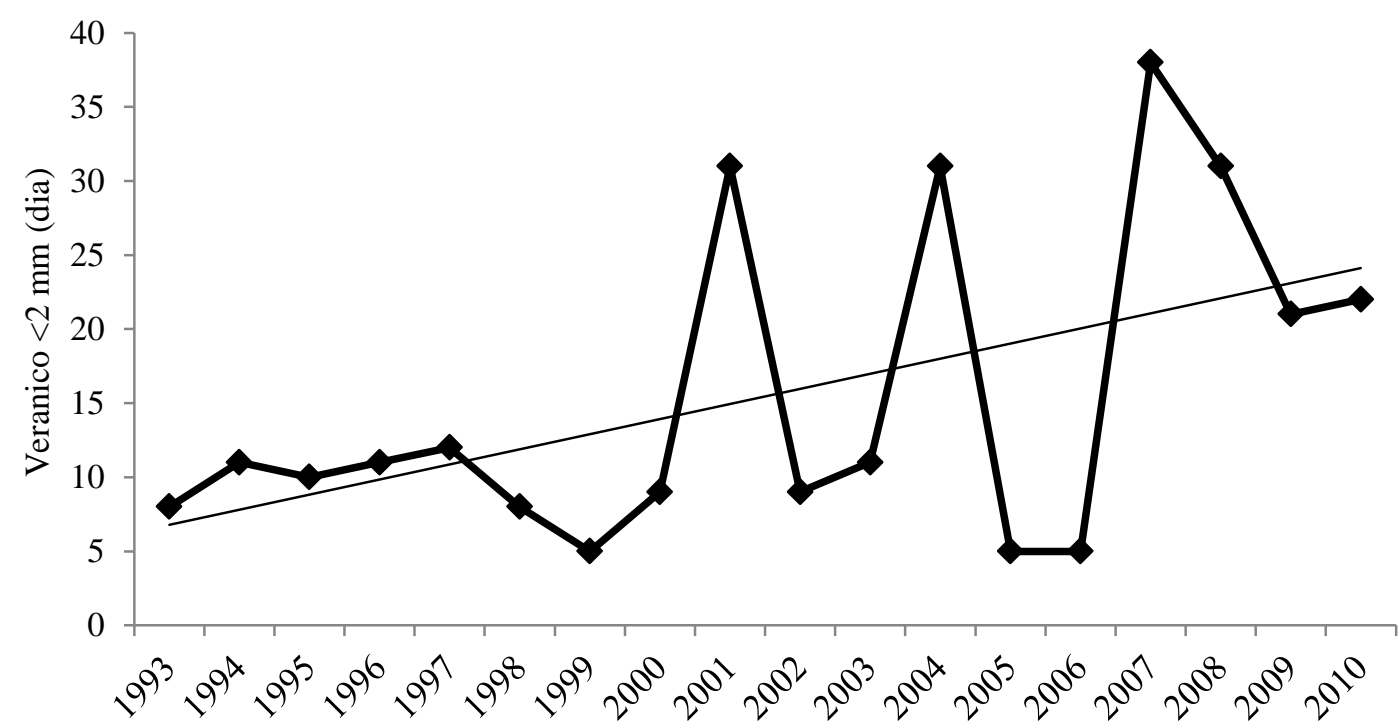


Na Tabela 1, são apresentados os coeficientes de correlação linear entre os maiores veranicos ocorridos e a produção agrícola de arroz, cana-de-açúcar, fava, feijão, mandioca, milho, banana e laranja.

Os coeficientes de correlação indicaram uma associação negativa entre a produção e a duração dos veranicos para as culturas de fava, mandioca e laranja. Para a produção de laranja, o coeficiente de correlação linear teve significância estatística de 95\%. Esses resultados estão de acordo com o observado por Menezes et al. (2010), que identificaram grande dependência entre a produção de milho e feijão e a duração dos veranicos no Estado da Paraíba, no período de 1975 a 1994.
Para a produção agrícola de arroz, cana-deaçúcar, feijão, milho e banana, o coeficiente de correlação linear entre os maiores veranicos foi positivo. Tendo a produção de milho com $95 \%$ de significância estatística e a produção de banana com $99 \%$ de significância.

Ressalta-se que a produção agrícola de banana, com maior significância estatística dentre as estudadas, foi diretamente proporcional aos maiores veranicos para o período analisado.

As produções de arroz, cana-de-açúcar, fava, feijão e mandioca independem da duração dos veranicos para o município de Santa Filomena - PI.

Tabela 1. Coeficientes de correlação linear entre os maiores veranicos no município de Santa Filomena - PI e as produções agrícolas de arroz (em casca), cana-de-açúcar, fava (em grão), feijão (em grão), mandioca, milho (em grão), banana (cacho) e laranja no período de 1993 a 2010.

\begin{tabular}{cccccccc}
\hline Arroz & Cana-de-açúcar & Fava & Feijão & Mandioca & Milho & Banana & Laranja \\
\hline 0,331 & 0,231 & $-0,281$ & 0,260 & $-0,260$ & $0,501 *$ & $0,694 * *$ & $-0,501 *$ \\
\hline
\end{tabular}

*95\% de significância; **99\% de significância.

\section{CONCLUSÕES}

De acordo com os resultados analisados, foi constatado que as produções agrícolas de milho e banana (95 e 99\% de significância estatística) no município de Santa Filomena - PI apresentaram relações diretamente proporcionais aos maiores veranicos ocorridos no período estudado, devido boa parte da produtividade agrícola das referidas culturas utilizar-se da irrigação.

Para a produção de laranja, obteve-se proporcionalidade inversa em relação aos maiores veranicos para Santa Filomena - PI, com 95\% de significância estatística.

As produções de arroz, cana-de-açúcar, fava, feijão e mandioca foram independentes da duração de veranicos, não obtendo significância estatística.

\section{REFERÊNCIAS}

BRUNI, A. L. Estatística aplicada à gestão empresarial. São Paulo: Atlas, 2007. 396 p.

BUSSAB, W. O.; MORETTIN, P. A. Estatística Básica. Atual Editora Ltda, São Paulo - SP. 4a Ed., 322p., 1987.

CARVALHO, D. F.; OLIVEIRA, M. A. A.; SOUSA, S. A. V.; CARVALHO, P. O. L. Estimativas de ocorrência de veranicos em Seropédica, Vassouras e Piraí (RJ), e suas influências no rendimento da cultura do feijão (Phaseolus Vulgaris L.). Ciência e Agrotecnologia, v.23, n.2, p.323$330,1999$.

IBGE. Disponível em: <http://www.ibge.gov.br>. Acesso em: set. 2014

MENEZES, H. E. A. Influência da temperatura da superfície dos oceanos Tropicais na ocorrência de veranicos no Estado da Paraíba. Dissertação de Mestrado em Meteorologia, UFCG, Campina Grande - PB, 2006.

MENEZES, H. E. A.; BRITO, J. I. B.; LIMA, R. A. F. A. Veranico e a produção agrícola no Estado da Paraíba,
Brasil. Revista Brasileira de Engenharia Agrícola e Ambiental, v.14, n.2, p.181-186, 2010.

MENEZES, H. E. A.; SILVA, R. M.; ALVES, L. M.; CAMARGO JÚNIOR, H. Verificação do prognóstico de precipitação sazonal simulada pelo modelo Eta climático para o Nordeste do Brasil. In: Congresso Brasileiro de Agrometeorologia, XIII, 2003, Santa Maria-RS. Anais: Santa Maria-RS: SBA, 2003, p. 999-1000.

MOREIRA, A. A. M. A influência da circulação de macro escala sobre o clima de Belo Horizonte: estudo sobre as possíveis influências do fenômeno El Niño sobre o clima local. 186p. Dissertação (Mestrado) - Universidade Federal de Minas Gerais, Belo Horizonte, 1999.

MOREIRA, J. L. B. Estudo da distribuição espacial das chuvas em Belo Horizonte e em seu entorno. 186p. Dissertação (Mestrado) - Universidade Federal de Minas Gerais, Belo Horizonte, 2002.

MORETTIN, L. G. Estatística Básica. Editora McGrawHill do Brasil Ltda, São Paulo - SP. 6ª Ed., 183p., 1991.

NOBRE, P.; MELO, A. B. C. Variabilidade climática intrasazonal sobre o Nordeste do Brasil em 1998-2000. Revista Climanálise, 2001.

NOBRE, P. MOURA, A. D.; SUN, L. Dynamical downscaling of seasonal climate prediction over Nordeste Brazil with ECHAM3 and NCEP's regional spectral models at IRI. Bulletin of the American Meteorological Society, p. 2787-796, 2001.

SANTOS, D. C.; MEDIROS, R. M.; SANTOS, D. C.; BRITO, J. I. B. Balanço hídrico climatológico e erosividade em função das mudanças climáticas em Santa Filomena - PI/Brasil. Revista Pernambucana de Tecnologia, Recife, v. 2, n. 2, p. 29-37, 2014.

SILVA, L. L.; COSTA, R. F.; CAMPOS, J. H. B. C.; DANTAS, R. T. Influência das precipitações na 
produtividade agrícola no Estado da Paraíba. Revista Brasileira de Engenharia Agrícola e Ambiental, v.13, n.4, p.454-461, 2009.

SILVA, V. P. R.; GUEDES, M. J. F.; LIMA, W. F. A.; CAMPOS, J. H. B. C. Modelo de previsão de rendimento de culturas de sequeiro, no semi-árido do Nordeste do Brasil. Revista Brasileira de Engenharia Agrícola e Ambiental, v.6, n.1, p.83-87, 2002.

SOUSA, S. A. V.; FRIZZONE, J. A. Simulação da Ocorrência de Veranicos em Piracicaba e seu Efeito em Duas Épocas de Plantio de Milho. In: Anais: X Congresso Brasileiro de Meteorologia, Piracicaba, 1997.

SPIEGEL, M. R. Estatística. Editora McGraw-Hill do Brasil Ltda, São Paulo - SP. Coleção Schaum. 581p. 1977.

VIANELLO, R. L.; ALVES, A. R. Meteorologia básica e aplicações. Viçosa, ed. UFV, 2000. 448p. 